\title{
Relationship between Inter-Limb Asymmetries and Physical Performance in Rink Hockey Players
}

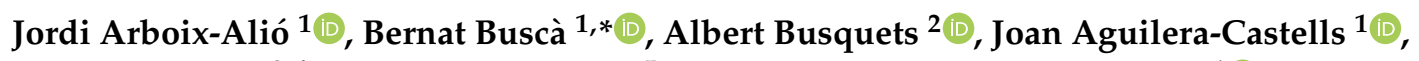 \\ Bernat de Pablo ${ }^{3,4}$, Alicia M. Montalvo ${ }^{5}$ and Azahara Fort-Vanmeerhaeghe ${ }^{1}$ (I) \\ 1 Faculty of Psychology, Education Sciences and Sport Blanquerna, Ramon Llull University, \\ 08022 Barcelona, Spain; jordiaa1@blanquerna.url.edu (J.A.-A.); joanac1@blanquerna.url.edu (J.A.-C.); \\ azaharafv@blanquerna.url.edu (A.F.-V.) \\ 2 National Institute of Physical Education of Catalonia (INEFC), University of Barcelona, \\ 08038 Barcelona, Spain; albert.busquets@gencat.cat \\ 3 Futbol Club Barcelona, 08002 Barcelona, Spain; bernat.depablo@ext.fcbarcelona.cat \\ 4 Real Federación Española de Patinaje, 28037 Madrid, Spain \\ 5 College of Health Solutions, Arizona State University, Phoenix, AZ 85004, USA; alicia.monta@gmail.com \\ * Correspondence: bernatbs@blanquerna.url.edu; Tel.: +34-93-253-3000
}

Received: 24 November 2020; Accepted: 7 December 2020; Published: 9 December 2020

\begin{abstract}
The magnitude of inter-limb asymmetries has been reported in several studies in different team sports but only some of them have analysed their effects on sports performance. The main purpose of this cross-sectional study was to determine inter-limb asymmetries and examine their relationship with different physical performance tests in rink hockey players. Nineteen rink hockey players (age: $23.37 \pm 4.82$ years; body height: $1.75 \pm 0.06 \mathrm{~cm}$; body mass: $73.16 \pm 9.87 \mathrm{~kg}$ ) performed a mid-season battery of fitness tests consisting of $30 \mathrm{~m}$ sprint, countermovement jump (CMJ), and half back squat. Inter-limb asymmetries were assessed using the single leg vertical countermovement jump test (SLCJ-V), single leg horizontal countermovement jump test (SLCJ-H), and $180^{\circ}$ change of direction test (COD). Results show a significant relationship between asymmetry in the SLCJ-H test, $30 \mathrm{~m}$ sprint $(\mathrm{r}=0.63, p<0.01)$ and CMJ performances $(\mathrm{r}=-0.52, p<0.05)$. Additionally, asymmetry in the SLCJ-V showed a significant relationship with CMJ performance $(\mathrm{r}=-0.46, p<0.05)$. These findings suggest that training programs should aim to reduce the inter-limb asymmetries in rink hockey players to improve their performance. Practitioners and coaches can use this information to assess the potential impact of asymmetries on physical performance in rink hockey players.
\end{abstract}

Keywords: roller hockey; imbalance; performance reduction

\section{Introduction}

Rink hockey is an intermittent team-sport characterized by different unilateral high intensity actions (accelerations, tackles, shoots, changes of direction (COD) or sudden braking) [1]. These characteristics make injury prevention an important part of the training process, in order to ensure performance and players' availability throughout the season [2]. Inter-limb asymmetries are considered an injury risk factor due to the high neuromuscular demand for the aforementioned actions. Indeed, the neuromuscular imbalances could result in lower limb muscular and joint injuries in team sports [3]. Thus, assessing the performance differences between limbs in jumping and COD actions provides valuable information to prevent neuromuscular disorders caused by the characteristics of these sports $[4,5]$.

There are different tests to measure inter-limb asymmetries. Isokinetic tests are typically used to measure inter-limb asymmetry [6] but are cost prohibitive and unhelpful for measuring sport-specific 
tasks. As such, in sport performance, there has been a shift away from isokinetic dynamometry and practitioners have moved towards more functional tasks, including unilateral jumps tests. These tests are used because they mimic unilateral sport-specific actions where the stretch-shortening cycle is used to generate power [7]. Furthermore, jump tests are widely used in sport performance analysis to determine the athlete's physical condition both during rehabilitation [8] and to detect inter-limb asymmetries in healthy athletes [9].

The use of inter-limb asymmetries to compare the performance between limbs has been widely investigated in many team sports, including football [10,11], basketball [12,13], rugby [14], volleyball [9], and rink hockey $[15,16]$. However, the relationship of inter-limb asymmetries with athletic performance is less studied. Whilst it seems logical to assume that minimising functional differences between limbs is desirable for injury prevention, its connection to physical performance remains unclear [4]. Certain evidence shows that inter-limb asymmetries result in decreased jump height [17], change of direction speed times [18], and are correlated with decreases in sprint speed [19]. Moreover, Bishop et al. [20] highlighted that inter-limb asymmetries for the single leg vertical countermovement jump test (SLCJ-V) were correlated with reduced jump performance and acceleration ability in youth female soccer players. In contrast, other studies have shown no relationship between lower-limb asymmetries and performance $[21,22]$. Therefore, the link between reduced inter-limb asymmetries and sports performance is still controversial.

Observing that recent literature has reported conflicting findings, further studies are needed to determine the relationship between inter-limb asymmetries and athletic performance. Furthermore, to the authors' knowledge, such studies in rink hockey players do not currently exist. Therefore, the aims of this study were: (1) to establish the magnitude and directionality of asymmetries in jump and COD skill and, (2) to examine the relationship between inter-limb asymmetries and physical performance. It was hypothesized that rink hockey players with larger inter-limb asymmetry values in unilateral tests would be correlated with reduced physical performance.

\section{Materials and Methods}

A cross-sectional design was used to determine the relationships between inter-limb asymmetries and physical performance in rink hockey players. A mid-season fitness testing battery over the course of two consecutive days was conducted.

To determine the inter-limb asymmetries, vertical and horizontal unilateral jumping and COD speed were assessed with single leg vertical countermovement jump (SLCJ-V), single leg horizontal countermovement jump (SLCJ-H), and COD tests, respectively. Physical performance was assessed with the following tests: countermovement jump (CMJ), half back squat, and $30 \mathrm{~m}$ sprint.

\subsection{Subjects}

Nineteen male rink hockey players (mean age $=23.37 \pm 4.82$ years; height $=1.75 \pm 0.06 \mathrm{~m}$; body mass $=73.16 \pm 9.87 \mathrm{~kg}$; body mass index $=23.58 \pm 2.44 \mathrm{~kg} \cdot \mathrm{m}^{-2}$; body fat percentage $=11.45 \pm 3.74 \%$ ) were voluntarily recruited to participate in the study. All players included in the study were training a minimum of four times per week (approximately 8 to $12 \mathrm{~h} /$ week), 9-10 months per year, and play at least one game every weekend throughout the season. Athletes were excluded from participation if they had any injury (acute or chronic) or illness at the time of the tests that prevented them from exerting maximum effort. Before participation in the study, written informed consent was obtained from all participants. The design of the research was in accordance with the Declaration of Helsinki (revised in Fortaleza, Brazil, 2013) and was approved by the ethics committee of the Ramon Llull University in Barcelona (ref. no. 1819005D). In addition, the technical department of the club provided their consent to conduct the study. 


\subsection{Procedures}

The first set of data were collected during a regular training session that fell $72 \mathrm{~h}$ after a match and was preceded by a rest day. Following a $24-48 \mathrm{~h}$ rest period, the second set of data were collected. On the first day, participants completed the SLCJ-V, SLCJ-H, and CMJ tests; while on the second day, they completed the COD, and half back squat, and $30 \mathrm{~m}$ sprint. All the tests were carried out on a covered sports court $(40 \times 20 \mathrm{~m})$ of terrazzo flooring. Participants were asked not to intake alcoholic beverages, caffeine, or do intense physical activity $24 \mathrm{~h}$ before the tests. They were also asked to refrain from eating for the two hours before the tests. A standardized $15 \mathrm{~min}$ warm-up (continuous moderate intensity running, joint mobility exercises, and progressive speed changes up to maximum intensity) was performed prior to the start of the test. Upon completion of the warm-up, participants completed three progressive practice trials for each test at 75, 90, and 100\% of their perceived maximal effort. Participants were allowed to rest for three minutes between the last practice trial and the beginning of the test.

Two repetitions were performed for each test. For the unilateral tests, participants started with their preferred leg and then alternated legs during the unilateral tests. A 3 min rest period was allowed to minimize fatigue. The best attempt of each test was used for the analysis.

\subsubsection{Single Leg Countermovement Jumps}

Participants completed two successful trials on each leg for both the vertical (SLCJ-V) and the horizontal (SLCJ-H) unilateral jumps. Previously, participants were instructed to perform a jump (vertical or horizontal) with one leg after an elastic countermovement. During the action of knee and hip flexion, participants were instructed to keep the trunk as straight as possible to avoid any possible influence of trunk muscles on the jump performance and hands remaining on the hips. They were asked to land on both feet at the same time too.

The SLCJ-V was assessed following the protocol described by Meylan et al. [23] and distance was calculated from flight time according to the Bosco protocol with a contact mat system (Chronojump-Boscosystem version 1.9.0, Barcelona, Spain). For the SLCJ-H, distance was measured with a measuring tape fixed to the floor and the participant started with the selected leg positioned just behind a starting line. The described tests have an excellent reliability $[6,23,24]$.

\subsection{2. $180^{\circ}$ Change of Direction Speed Test (COD Test)}

The COD time performance test was measured using a photocell beam (Velleman PME10D; Velleman, Inc., Gavere, Belgium) connected to a computer (Chronojump-Boscosystem, Barcelona, Spain) and located $1.3 \mathrm{~m}$ from the ground level. Previous research has recommended this height to avoid the interference of arm action in these types of measurements [25]. The test was performed wearing skates to reproduce specific rink hockey change of direction [26]. For the COD measurement, players were instructed to skate forward for five meters and return to the starting line as fast as possible, skating a total distance of ten meters. Participants were instructed to perform the test by braking on one side, and alternatively performing the same test with the other leg for two attempts. A trial was considered successful if the participant passed the line with the foot during the COD. This test reported good test-retest reliability [27].

\subsubsection{Countermovement Jump (CMJ)}

The CMJ was used to assess the explosive strength of the lower limbs. The test was performed using a contact mat (Chronojump-Boscosystem, Barcelona, Spain) [28]. Vertical jump height was calculated from the flight time using Chronojump software (version 1.9.0). During the CMJ, participants were asked to keep their hands on their hips and to self-select the depth of the countermovement. Participants were also instructed to land in an upright and balanced position. Jumps were separated by a rest period of $20 \mathrm{~s}$. 


\subsubsection{Half Back Squat}

The half back squat was used to assess the average power of the lower limbs. Participants started in an upright position looking forward with both hands firmly grasping the bar, which was positioned squarely on the shoulders. The initial position was full knee and hip extension, situating the barbell at shoulder-level and feet at shoulder-width distance. An adjustable-height bench was placed behind the subjects to determine the depth of half squat. The squats were performed with a load ( $\sim 60 \%$ of the maximum repetition) that allowed $1 \mathrm{~m} / \mathrm{s}$ of movement [29]. A linear position transducer (Chronojump-Boscosystem, Barcelona, Spain), sampling at $1000 \mathrm{~Hz}$, fixed to the bar at a perpendicular angle to the floor, was used to measure speed during testing. The test was performed two times, separated by a 3 min rest, and the best trial was used for the analysis.

\subsection{5. $30 \mathrm{~m}$ Sprint}

The $30 \mathrm{~m}$ sprint was used to assess sprint speed. Cones were used to establish the starting and finishing lines. The participants completed two trails with a 3 min rest period. The MySprint app (Apple Inc., Cupertino, CA, USA) was used as a timing system. This screening tool has shown an excellent intra- and inter-rater reliability for the $30 \mathrm{~m}$ sprint test [30]. The best of the two sprint times was used for the analysis. In order to reproduce a higher specificity of rink hockey action, players performed the test on skates [31].

\subsection{Statistical Analysis}

Statistical analyses were performed using SPSS (version 20 for Windows; SPSS Inc., Chicago, IL, USA). For all variables, the data were expressed as mean and standard deviation (SD). The Shapiro-Wilk test was used to determine the normality of the variables. In addition, within-session reliability of test measures was analysed using a two-way random intraclass correlation coefficient (ICC) with an absolute agreement ( $95 \%$ confidence intervals). Intraclass correlation coefficient (ICC) values were considered as $>0.9=$ excellent, $0.75-0.9=$ good, $0.5-0.75=$ moderate, and $<0.5=$ poor, respectively [32]. Additionally, the coefficient of variation (CV) was calculated and a value of $<10 \%$ was considered as acceptable [33]. The t-Student for related samples test was used to establish the differences between the legs on the different single-leg tests. The magnitude of the difference was determined using Cohen's $d$ effect sizes (ES) [34]. Values were interpreted as $<0.20=$ trivial, $0.20-0.60=$ small, $0.61-1.20=$ moderate, $1.21-2.0=$ large and $>2.0=$ very large following Hopkins et al. [35]. The kappa coefficient was calculated to determine the consistency of asymmetries direction [5] and it was interpreted as $\leq 0=$ poor, $0.01-0.20=$ slight, $0.21-0.40=$ fair, $0.41-0.60=$ moderate, $0.61-0.80=$ substantial, and $0.81-0.99=$ almost perfect [36]. This method quantifies how much the observed agreement between raters exceeds agreement due to chance alone [37]. In order to identify inter-limb asymmetry magnitude, the asymmetry index (ASI) was calculated using the previously recommended formula for unilateral tests [38-40]:

$$
\mathrm{ASI} \%=\frac{\text { Highest Performing Limb }- \text { Lowest Performing Limb }}{\text { Highest Performing Limb }} \times 100
$$

The highest performing limb (HPL) was defined as the side with the best value for each task, while the other limb was defined as the lowest performing limb (LPL).

Pearson's correlations were used to compare ASI scores (SLCJ-V, SLCJ-H, and COD) with physical performance tests (CMJ, half back squat, and $30 \mathrm{~m}$ sprint). Statistical significance was established at $p \leq 0.05$. Magnitudes of correlation were interpreted as $0.00-0.09=$ trivial, $0.10-0.29=$ small, $0.30-0.49=$ moderate, $0.50-0.69=$ large, $0.70-0.89=$ very large, $0.90-0.99=$ nearly perfect, and $1.00=$ perfect, following Hopkins' scale [35]. 


\section{Results}

Descriptive statistics and reliability measures for all tests are shown in Table 1.

Table 1. Test scores (mean $\pm \mathrm{SD}$ ), within-session reliability data, inter-limb asymmetry values and effect sizes.

\begin{tabular}{|c|c|c|c|c|c|c|c|}
\hline Test & Mean \pm SD & ICC & $95 \%$ CI & CV (\%) & ASI & $p$ Value & ES \\
\hline SLCJ-V HPL (cm) & $22.99 \pm 2.79$ & 0.956 & $0.88-0.98$ & 2.55 & \multirow[b]{2}{*}{$8.09 \pm 6.86$} & \multirow[b]{2}{*}{0.001} & \multirow[b]{2}{*}{0.617} \\
\hline SLCJ-V LPL (cm) & $21.16 \pm 3.13$ & 0.919 & $0.81-0.97$ & 2.71 & & & \\
\hline SLCJ-H HPL (cm) & $189.52 \pm 6.93$ & 0.954 & $0.90-0.98$ & 2.79 & \multirow[b]{2}{*}{$2.91 \pm 2.62$} & \multirow[b]{2}{*}{$<0.001$} & \multirow[b]{2}{*}{0.695} \\
\hline SLCJ-H LPL (cm) & $184.11 \pm 10.15$ & 0.894 & $0.84-0.99$ & 2.76 & & & \\
\hline COD HPL (s) & $2.77 \pm 0.06$ & 0.964 & $0.76-0.99$ & 5.09 & \multirow{2}{*}{$2.16 \pm 1.55$} & \multirow[b]{2}{*}{0.004} & \multirow{2}{*}{1.000} \\
\hline COD LPL (s) & $2.83 \pm 0.06$ & 0.936 & $0.69-0.99$ & 5.11 & & & \\
\hline $\mathrm{CMJ}(\mathrm{cm})$ & $41.28 \pm 5.07$ & 0.947 & $0.49-0.99$ & 2.15 & & & \\
\hline Half back squat (W) & $2791.39 \pm 653.99$ & 0.982 & $0.86-0.99$ & 1.69 & & & \\
\hline 30-m sprint (s) & $4.39 \pm 0.27$ & 0.964 & $0.59-0.99$ & 1.05 & & & \\
\hline
\end{tabular}

Key: $\mathrm{SD}$ = standard deviation; ICC $=$ intraclass correlation coefficient; $\mathrm{CI}=$ confidence intervals; $\mathrm{CV}=$ coefficient of variation; ASI = asymmetry index; ES = Cohen's $d$ effect size; HPL = highest performing limb; LPL = lowest performing limb; SLCJ-V = single leg vertical countermovement jump; SLCJ-H = single leg horizontal countermovement jump; $\mathrm{COD}$ = change of direction capacity; $\mathrm{CMJ}=$ countermovement jump.

Results of the paired $t$-tests (Table 1) showed significant differences between the HPL and LPL across all tasks $(p<0.001)$ with a moderate difference magnitude (ES $>0.6)$. The mean ASI magnitude ranged between $2.16 \%$ and $8.09 \%$ depending on the test. Additionally, kappa coefficients and descriptive agreement showed different directionality depending on the test (kappa $=-0.36$ to 0.23) (Table 2).

Table 2. Kappa coefficients of asymmetries.

\begin{tabular}{ccc}
\hline Test Comparison & Kappa Coefficient & Descriptor \\
\hline SLCJ-V vs. SLCJ-H & 0.27 & Fair \\
SLCJ-V vs. COD & -0.20 & Poor \\
SLCJ-H vs. COD & -0.36 & Poor \\
\hline
\end{tabular}

Key: SLCJ-V = single leg vertical countermovement jump; SLCJ-H = single leg horizontal countermovement jump; $\mathrm{COD}=$ change of direction capacity.

Figure 1 displays the individual inter-limb asymmetries for the different tests with positive values indicating right dominance and negative values indicating left dominance.

Results show a significant correlation with a large magnitude between the SLCJ-H asymmetry and the $30 \mathrm{~m}$ sprint test performance and negative correlations between CMJ performance and asymmetries from SLCJ-H and SLCJ-V (Table 3).

Table 3. Pearson's correlations (r) between asymmetries and performance test.

\begin{tabular}{cccc}
\hline Test & SLCJ-V (\%) & SLCJ-H (\%) & COD (\%) \\
\hline CMJ & $-0.46^{*}$ & $-0.52^{*}$ & 0.12 \\
Half back squat & -0.37 & -0.45 & 0.31 \\
30-m sprint & 0.34 & $0.63^{* *}$ & -0.01 \\
\hline
\end{tabular}

Key: SLCJ-V = single leg vertical countermovement jump; SLCJ-H = single leg horizontal countermovement jump; $\mathrm{COD}=$ change of direction capacity; CMJ = countermovement jump; ${ }^{*}(p<0.05) ;{ }^{* *}(p<0.01)$. 


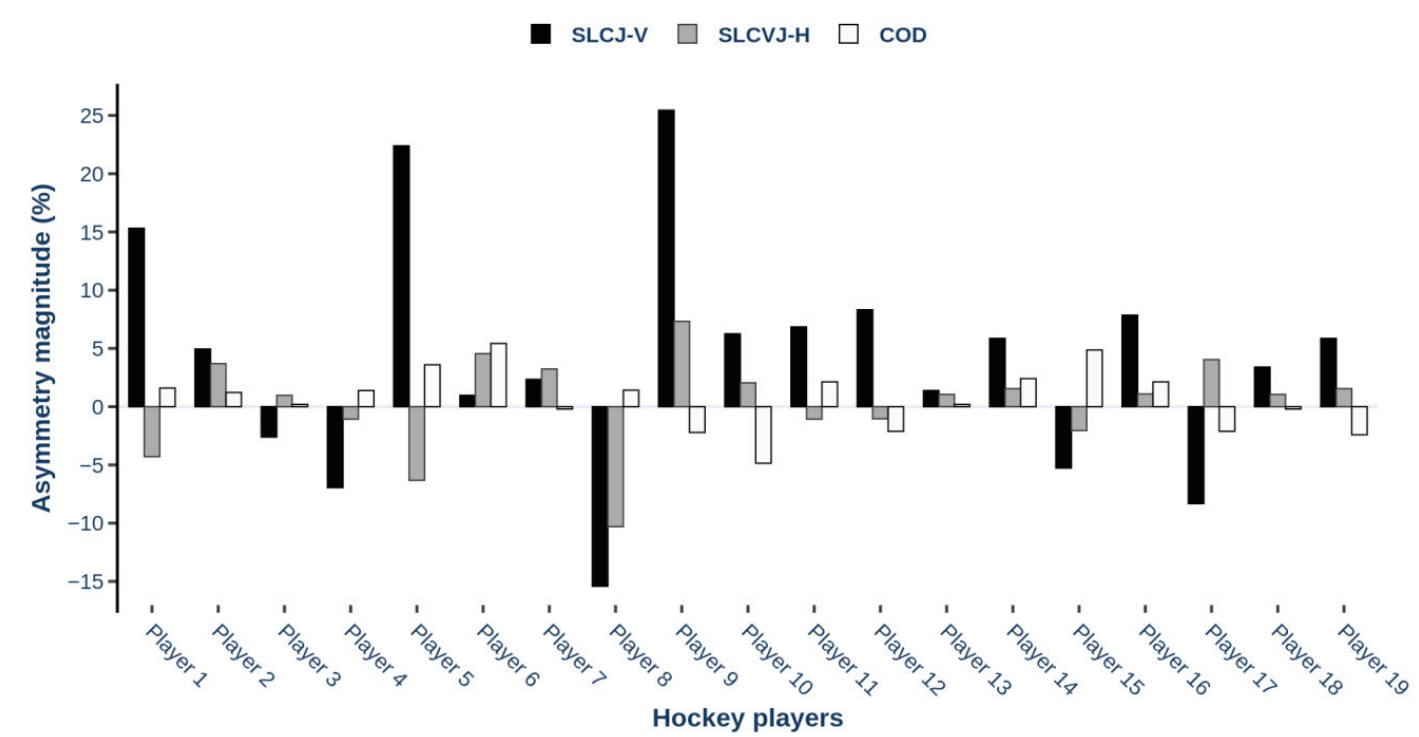

Figure 1. Percentage of asymmetry index (ASI) for each participant and task (positive = right leg dominance; negative = left leg dominance).

\section{Discussion}

The present study aimed to determine the magnitude and directionality of asymmetries in SLCJ-V, SLCJ-H and COD tests in rink hockey players and to evaluate its relationship with the physical performance tests. The main findings were that different asymmetry magnitudes were found among tests, with the SLCJ-V showing the greatest asymmetry values. Results also show that higher inter-limb asymmetries (large magnitude) observed in the SLCJ-H test were related with lower $30 \mathrm{~m}$ sprint performance. The same asymmetry index was also associated with reduced jump height on the CMJ test. Additionally, the ASI\% differed between functional tests and rarely favoured the same side.

Good to excellent reliability (ICC range $=0.894-0.964$ ) was observed, providing confidence for further analysis [41]. In this vein, high standard athletes experienced in strength and conditioning training (high demanding neuromuscular training) report good reliability of the assessments [42].

The first finding of this study was the significant differences found between HPL and LPL in all tests. Significant differences between legs are a common finding and can be explained by sport-specific demands, such as unilateral actions $[9,43]$. In rink hockey, unilateral sport-specific demands include constant changes of trajectory, asymmetric displacement due to the stick grip and technical passing/shooting actions [15]. These demands, executed at high intensities, might develop differentiated neuromuscular adaptations and, therefore, inter-limb asymmetries throughout the player's life. Thus, the ASI mean did not exceed $10 \%$ for any of the tests. The literature suggests that an ASI value greater than $10-15 \%$ on the vertical jump test is related to an increased risk of injury $[24,44,45]$. The highest mean was obtained in the SLCJ-V test $(8.09 \pm 6.86 \%)$. This value is slightly lower than the mean reported by Arboix-Alió et al. [16] (9.60\%) in a similar sample. Similarly, the ASI mean values for the SLCJ-H $(2.91 \pm 2.62 \%)$ and COD $(2.16 \pm 1.55 \%)$ tests were also lower than those reported by Arboix-Alió et al. [16]. The SLCJ-V test had the highest ASI according to other similar studies with different team-sport athletes $[3,13]$. In line with the existing literature, this finding indicates that this test is probably the most sensitive to detect inter-limb asymmetries [20,21].

In the present study, the HPL differed for each test in several players, which demonstrates that there is a high variability in the asymmetry direction when comparing the different tests. The kappa coefficient, calculated to know the direction of asymmetries, showed only "fair" side consistency of asymmetry between tests ( -0.36 to 0.23$)$. These results are in accordance with Arboix-Alió et al. [16] who found no significant relationships between the asymmetry values of different neuromuscular tests in rink hockey players. In line with other studies in different team sports, the present investigation 
failed to demonstrate the relationship between asymmetry scores on different tests $[13,46,47]$. Thus, following the idea of Gonzalo-Skok et al. [48] about the specific adaptations of the neuromuscular system in producing multidirectional forces in the vertical and horizontal dimension, the present findings suggest that different mid- and long-term training effects might differently influence the amount of forces produced by both limbs in the standard tests. Furthermore, the nature of rink hockey actions with accentuated decelerations probably enhance the differences in neuromuscular limb adaptations due to its eccentric overload [49]. This finding suggests that asymmetry values are independent from each test and reflects the importance of assessing a variety of neuromuscular tests or to choose the correct one for this purpose depending on the sport discipline.

With regard to physical performance, there was a significant correlation between jump height SLCJ-H asymmetry and $30 \mathrm{~m}$ sprint time. Additionally, CMJ height was negatively correlated with SLCJ-H and SLCJ-V asymmetry. Players with high vertical jump performance had lower ASI values on both neuromuscular tests $(r=-0.52$ and $r=-0.46$, respectively). Although no data are available for rink hockey players, several studies have shown similar findings in different team-sports. In soccer, Bishop et al. $[20,50]$ found significant correlations between SLCJ-V height asymmetry and reduced sprinting performance in both female and male players. Similarly, Fort-Vanmeerhaeghe et al. [19] reported negative correlations between SLCJ-V asymmetry and sprint performance in basketball players. Conversely, in this study, no significant correlations were found between COD inter-limb asymmetries and the jump or sprint tests, in contrast with reported research showing significant correlations between inter-limb asymmetries and COD speed decrements [51,52]. The players of the present study performed the COD test on skates instead of sports shoes. This difference in the footwear probably converts this test into a player's technique assessment rather than a simple COD test assessing a physical ability. In rink hockey, similar to many team-sports, the ability to accelerate, reverse, or effectively change the direction and re-accelerate during the game is crucial. However, in rink hockey the key to successful COD skills lies more in the efficiency of the player's skating technique than in their physical condition. This could be explained by the same reasons reported by Arboix-Alió et al. [26,31] who did not find significant correlations between the same tests performed with and without skates.

Despite the utility of these findings, there are some limitations that should be acknowledged. The main limitation was the cross-sectional nature of this study, excluding any causal connection between the different asymmetries. Additionally, the results of the present research are only representative of the time the tests were carried out (middle of the season) and, therefore, may change at different moments throughout the season. For this reason, more research is required to compare the magnitudes and directions of asymmetries throughout the season. Moreover, future work should aim to compare the different asymmetries by competitive level. Although there is certain evidence regarding the inconsistency of the asymmetry direction of the different tests in high-level players [4,53], further research could help to identify the need for the best training interventions. Additionally, future research should expand the sample and categorize findings by position (goalkeeper, defender, or striker) as results may vary by positional demands. Finally, further studies could analyse the relationship between asymmetries and different match load variables (i.e., distance covered, amount of high-speed running, etc.) to understand the role of inter-limb asymmetries on performance in rink hockey.

\section{Conclusions}

In conclusion, the current study found that higher SLCJ-H asymmetries were correlated with lower $30 \mathrm{~m}$ sprint performance and reduced CMJ height, but not with $180^{\circ} \mathrm{COD}$ test. The results also indicate that players obtained significant differences between the HPL and LPL in all neuromuscular tasks and that the ASI values showed a different directionality, highlighting the lack of consistency of inter-limb differences across tests. 
In light of these results, it is suggested that training programs should aim to reduce inter-limb asymmetries in rink hockey players to improve physical performance. Therefore, a complete neuromuscular profile for both legs should be obtained using a fitness test battery involving a different variety of tests or those tests that discriminate the specific asymmetries for each sport the most. Determining the asymmetries could help practitioners to restructure the workload ratios for each limb in strength and conditioning training sessions.

Author Contributions: Conceptualization, J.A.-A., B.B., A.F.-V. and A.B.; methodology, B.B., J.A.-A. and A.F.-V.; formal analysis, B.B., J.A.-C., J.A.-A. and B.d.P.; data curation, B.B., J.A.-A. and J.A.-C.; funding acquisition, B.B.; investigation, J.A.-A., J.A.-C., B.B.; writing-original draft preparation, B.B., J.A.-A. and A.B.; writing-review and editing, B.B., J.A.-A., A.M.M., A.F.-V. and B.d.P.; project administration, B.B. All authors have read and agreed to the published version of the manuscript.

Funding: This research was funded by the Fundació Blanquerna, Ramon Llull University with grant number BRB1920-GRIES.

Acknowledgments: We are grateful to all the study subjects for their participation.

Conflicts of Interest: The authors declare no conflict of interest. The sponsors had no role in the design, execution, interpretation, or writing of the study.

\section{References}

1. Yagüe, P.L.; Del Valle, M.E.; Egocheaga, J.; Linnamo, V.; Fernández, A. The competitive demands of elite male rink hockey. Biol. Sport 2013, 30, 195-199. [CrossRef] [PubMed]

2. Bahr, R.; Krosshaug, T. Understanding injury mechanisms: A key component of preventing injuries in sport. Br. J. Sports Med. 2005, 39, 324-329. [CrossRef] [PubMed]

3. Fort-Vanmeerhaeghe, A.; Mila-Villarroel, R.; Pujol, M.; Arboix-Alió, J.; Bishop, C. Higher Vertical Jumping Asymmetries and Lower Physical Performance are Indicators of Increased Injury Incidence in Youth Team-Sport Athletes. J. Strength Cond. Res. 2020. [CrossRef] [PubMed]

4. Bishop, C.; Turner, A.; Read, P. Effects of inter-limb asymmetries on physical and sports performance: A systematic review. J. Sports Sci. 2018, 36, 1135-1144. [CrossRef] [PubMed]

5. Bishop, C.; Lake, J.; Loturco, I.; Papadopoulos, K.; Turner, A.; Read, P. Interlimb Asymmetries: The need for an individual approach to data analysis. J. Strength Cond. Res. 2018. [CrossRef]

6. Maulder, P.; Cronin, J. Horizontal and vertical jump assessment: Reliability, symmetry, discriminative and predictive ability. Phys. Ther. Sport 2005, 6, 74-82. [CrossRef]

7. Ceroni, D.; Martin, X.E.; Delhumeau, C.; Farpour-Lambert, N.J. Bilateral and Gender Differences During Single-Legged Vertical Jump Performance in Healthy Teenagers. J. Strength Cond. Res. 2012, 26, $452-457$. [CrossRef]

8. Brumitt, J.; Heiderscheit, B.C.; Manske, R.C.; Niemuth, P.E. Lower Extremity Functional Tests and Risk. Int. J. Sports Phys. Ther. 2013, 8, 216-227.

9. Fort-Vanmeerhaeghe, A.; Gual, G.; Romero-Rodriguez, D.; Unnitha, V. Lower limb neuromuscular asymmetry in volleyball and basketball players. J. Hum. Kinet. 2016, 50, 135-143. [CrossRef]

10. Daneshjoo, A.; Rahnama, N.; Mokhtar, A.H.; Yusof, A. Bilateral and unilateral asymmetries of isokinetic strength and flexibility in male young professional soccer players. J. Hum. Kinet. 2013, 36, 45-53. [CrossRef]

11. Hart, N.H.; Nimphius, S.; Weber, J.; Spiteri, T.; Rantalainen, T.; Dobbin, M.; Newton, R.U. Musculoskeletal Asymmetry in Football Athletes: A Product of Limb Function over Time. Med. Sci. Sports Exerc. 2016, 48, 1379-1387. [CrossRef] [PubMed]

12. Sugiyama, T.; Kameda, M.; Kageyama, M.; Kiba, K.; Kanehisa, H.; Maeda, A. Asymmetry between the Dominant and Non-Dominant Legs in the Kinematics of the Lower Extremities during a Running Single Leg Jump in Collegiate Basketball Players. J. Sports Sci. Med. 2014, 13, 951-957. [PubMed]

13. Fort-Vanmeerhaeghe, A.; Montalvo, A.M.; Sitjà-Rabert, M.; Kiefer, A.W.; Myer, G.D. Neuromuscular asymmetries in the lower limbs of elite female youth basketball players and the application of the skillful limb model of comparison. Phys. Ther. Sport 2015, 16, 317-323. [CrossRef] [PubMed] 
14. Marshall, B.; Franklyn-Miller, A.; Moran, K.; King, E.; Richter, C.; Gore, S.; Strike, S.; Falvey, É. Biomechanical symmetry in elite rugby union players during dynamic tasks: An investigation using discrete and continuous data analysis techniques. BMC Sports Sci. Med. Rehabil. 2015, 7, 13. [CrossRef]

15. Arboix-Alió, J.; Aguilera-Castells, J. Comparison between the dominant leg and the strong leg in roller hockey. J. Sport Health Res. 2020. Available online: http://www.journalshr.com (accessed on 29 April 2020).

16. Arboix-Alió, J.; Aguilera-Castells, J.; Rey-Abella, F.; Buscà, B.; Fort-Vanmeerhaeghe, A. Asimetrías neuromusculares entre miembros inferiores en jugadores de hockey sobre patines. RICYDE. Rev. Int. Cienc. Deport. 2018, 14, 358-373. [CrossRef]

17. Bell, D.R.; Sanfilippo, J.L.; Binkley, N.; Heiderscheit, B.C. Lean Mass Asymmetry Influences Force and Power Asymmetry During Jumping in Collegiate Athletes. J. Strength Cond. Res. 2014, 28, 884-891. [CrossRef]

18. Hoffman, J.R.; Ratamess, N.A.; Klatt, M.; Faigenbaum, A.D.; Kang, J. Do Bilateral Power Deficits Influence Direction-Specific Movement Patterns? Res. Sports Med. 2007, 15, 125-132. [CrossRef]

19. Fort-Vanmeerhaeghe, A.; Bishop, C.; Buscà, B.; Aguilera-Castells, J.; Vicens-Bordas, J.; Gonzalo-Skok, O. Inter-limb asymmetries are associated with decrements in physical performance in youth elite team sports athletes. PLOS ONE 2020, 15, e0229440. [CrossRef]

20. Bishop, C.; Read, P.; McCubbine, J.; Turner, A. Vertical and Horizontal Asymmetries are Related to Slower Sprinting and Jump Performance in Elite Youth Female Soccer Players. J. Strength Cond. Res. 2018. [CrossRef]

21. Lockie, R.G.; Callaghan, S.J.; Berry, S.P.; Cooke, E.R.A.; Jordan, C.A.; Luczo, T.M.; Jeffriess, M.D. Relationship Between Unilateral Jumping Ability and Asymmetry on Multidirectional Speed in Team-Sport Athletes. J. Strength Cond. Res. 2014, 28, 3557-3566. [CrossRef]

22. Dos'Santos, T.; Thomas, C.; Jones, P.A.; Comfort, P. Asymmetries in single and triple hop are not detrimental to change of direction speed. J. Trainol. 2017, 6, 35-41. [CrossRef]

23. Meylan, C.; McMaster, T.; Cronin, J.; Mohammad, N.I.; Rogers, C.; DeKlerk, M. Single-Leg Lateral, Horizontal, and Vertical Jump Assessment: Reliability, Interrelationships, and Ability to Predict Sprint and Change-of-Direction Performance. J. Strength Cond. Res. 2009, 23, 1140-1147. [CrossRef] [PubMed]

24. Hewit, J.; Cronin, J.; Hume, P. Multidirectional Leg Asymmetry Assessment in Sport. Strength Cond. J. 2012, 34, 82-86. [CrossRef]

25. Yeado, M.; Kato, T.; Kerwin, D. Measuring running speed using photocells. J. Sports Sci. 1999, 17, $249-257$. [CrossRef] [PubMed]

26. Arboix-Alió, J.; Aguilera-Castells, J.; Ferrándiz, C. Resistencia Aeróbica en Hockey Patines: Análisis Comparativo del Rendimiento Deportivo Efectuado con y sin Patines. Red Rev. Entren. Deport. 2016, 31, 1-10.

27. Castillo-Rodríguez, A.; Fernández-García, J.C.; Chinchilla-Minguet, J.L.; Carnero, E.Á. Relationship Between Muscular Strength and Sprints with Changes of Direction. J. Strength Cond. Res. 2012, 26, 725-732. [CrossRef]

28. Bosco, C.; Luhtanen, P.; Komi, P.V. A simple method for measurement of mechanical power in jumping. Eur. J. Appl. Physiol. Occup. Physiol. 1983, 50, 273-282. [CrossRef]

29. González-Badillo, J.J.; Pareja-Blanco, F.; Rodríguez-Rosell, D.; Abad-Herencia, J.L.; del Ojo-López, J.J.; Sánchez-Medina, L. Effects of Velocity-Based Resistance Training on Young Soccer Players of Different Ages. J. Strength Cond. Res. 2015, 29, 1329-1338. [CrossRef]

30. Romero-Franco, N.; Jiménez-Reyes, P.; Castaño-Zambudio, A.; Capelo-Ramírez, F.; Rodríguez-Juan, J.J.; González-Hernández, J.; Toscano-Bendala, F.J.; Cuadrado-Peñafiel, V.; Balsalobre-Fernández, C. Sprint performance and mechanical outputs computed with an iPhone app: Comparison with existing reference methods. Eur. J. Sport Sci. 2017, 17, 386-392. [CrossRef]

31. Arboix-Alió, J.; Aguilera-Castells, J.; Ferrándiz, C. Roller hockey: Correlative study about the speed capacity with and without skates. Rev. Int. Deport. Colect. 2017, 31, 18-31.

32. Koo, T.K.; Li, M.Y. A Guideline of Selecting and Reporting Intraclass Correlation Coefficients for Reliability Research. J. Chiropr. Med. 2016, 15, 155-163. [CrossRef] [PubMed]

33. Cormack, S.J.; Newton, R.U.; McGuigan, M.R.; Doyle, T.L.A. Reliability of Measures Obtained During Single and Repeated Countermovement Jumps. Int. J. Sports Physiol. Perform. 2008, 3, 131-144. [CrossRef] [PubMed]

34. Cohen, J. Statistical Power Analysis for Behavioural Science; Lawrence Erlbaum: Hillsdale, NJ, USA, 1988.

35. Hopkins, W.G.; Marshall, S.W.; Batterham, A.M.; Hanin, J. Progressive Statistics for Studies in Sports Medicine and Exercise Science. Med. Sci. Sports Exerc. 2009, 41, 3-13. [CrossRef] [PubMed] 
36. Viera, A.; Garrett, J. Understanding Interobserver Agreement: The Kappa Statistic. Fam. Med. 2005, 37, 360-363. [PubMed]

37. Cohen, J. A coefficient of agreement for nominal scales. Educ. Psychol. Meas. 1960, 20, 37-46. [CrossRef]

38. Carpes, F.P.; Mota, C.B.; Faria, I.E. On the bilateral asymmetry during running and cycling-A review considering leg preference. Phys. Ther. Sport 2010, 11, 136-142. [CrossRef]

39. Impellizzeri, F.M.; Rampinini, E.; Maffiuletti, N.; Marcora, S.M. A vertical jump force test for assessing bilateral strength asymmetry in athletes. Med. Sci. Sports Exerc. 2007, 39, 2044-2050. [CrossRef]

40. Bishop, C.; Read, P.; Chavda, S.; Turner, A. Asymmetries of the Lower Limb: The Calculation Conundrum in Strength Training and Conditioning. Strength Cond. J. 2016, 38, 27-32. [CrossRef]

41. Turner, A.; Brazier, J.; Bishop, C.; Chavda, S.; Cree, J.; Read, P. Data Analysis for Strength and Conditioning Coaches. Strength Cond. J. 2015, 37, 76-83. [CrossRef]

42. Bishop, C.; Berney, J.; Lake, J.; Loturco, I.; Blagrove, R.; Turner, A.; Read, P. Bilateral Deficit During Jumping Tasks. J. Strength Cond. Res. 2019. [CrossRef]

43. Schiltz, M.; Lehance, C.; Maquet, D.; Bury, T.; Crielaard, J.-M.; Croisier, J.-L. Explosive Strength Imbalances in Professional Basketball Players. J. Athl. Train. 2009, 44, 39-47. [CrossRef] [PubMed]

44. McElveen, M.T.; Riemann, B.L.; Davies, G.J. Bilateral Comparison of Propulsion Mechanics During Single-Leg Vertical Jumping. J. Strength Cond. Res. 2010, 24, 375-381. [CrossRef] [PubMed]

45. Munro, A.G.; Herrington, L.C. Between-Session Reliability of Four Hop Tests and the Agility T-Test. J. Strength Cond. Res. 2011, 25, 1470-1477. [CrossRef]

46. Bishop, C.; Turner, A.; Maloney, S.; Lake, J.; Loturco, I.; Bromley, T.; Read, P. Drop Jump Asymmetry is Associated with Reduced Sprint and Change-of-Direction Speed Performance in Adult Female Soccer Players. Sports 2019, 7, 29. [CrossRef] [PubMed]

47. Raya-González, J.; Bishop, C.; Gómez-Piqueras, P.; Veiga, S.; Viejo-Romero, D.; Navandar, A. Strength, Jumping, and Change of Direction Speed Asymmetries Are Not Associated With Athletic Performance in Elite Academy Soccer Players. Front. Psychol. 2020, 11, 175. [CrossRef] [PubMed]

48. Gonzalo-Skok, O.; Tous-Fajardo, J.; Suarez-Arrones, L.; Arjol-Serrano, J.L.; Casajús, J.A.; Mendez-Villanueva, A. Single-Leg Power Output and Between-Limbs Imbalances in Team-Sport Players: Unilateral Versus Bilateral Combined Resistance Training. Int. J. Sports Physiol. Perform. 2017, 12, 106-114. [CrossRef] [PubMed]

49. de Hoyo, M.; de la Torre, A.; Pradas, F.; Sañudo, B.; Carrasco, L.; Mateo-Cortes, J.; Domínguez-Cobo, S.; Fernandes, O.; Gonzalo-Skok, O. Effects of Eccentric Overload Bout on Change of Direction and Performance in Soccer Players. Int. J. Sports Med. 2014, 36, 308-314. [CrossRef]

50. Bishop, C.; Brashill, C.; Abbott, W.; Read, P.; Lake, J.; Turner, A. Jumping Asymmetries Are Associated With Speed, Change of Direction Speed, and Jump Performance in Elite Academy Soccer Players. J. Strength Cond. Res. 2019. [CrossRef]

51. Maloney, S.J.; Richards, J.; Nixon, D.G.D.; Harvey, L.J.; Fletcher, I.M. Do stiffness and asymmetries predict change of direction performance? J. Sports Sci. 2017, 35, 547-556. [CrossRef]

52. Madruga-Parera, M.; Bishop, C.; Read, P.; Lake, J.; Brazier, J.; Romero-Rodriguez, D. Jumping-based Asymmetries are Negatively Associated with Jump, Change of Direction, and Repeated Sprint Performance, but not Linear Speed, in Adolescent Handball Athletes. J. Hum. Kinet. 2020, 71, 47-58. [CrossRef]

53. Bishop, C.; Read, P.; Bromley, T.; Brazier, J.; Jarvis, P.; Chavda, S.; Turner, A. The Association Between Interlimb Asymmetry and Athletic Performance Tasks: A Season-Long Study in Elite Academy Soccer Players. J. Strength Cond. Res. 2020. [CrossRef] [PubMed]

Publisher's Note: MDPI stays neutral with regard to jurisdictional claims in published maps and institutional affiliations. 